\title{
Article \\ Diabetes Mellitus and Associated Factors in Slovakia: Results from the European Health Interview Survey 2009, 2014, and 2019
}

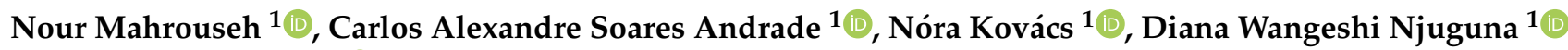 \\ and Orsolya Varga $1,2, *$ (D) \\ 1 Department of Public Health and Epidemiology, Faculty of Medicine, University of Debrecen, \\ 4032 Debrecen, Hungary; nour.mahrouseh@med.unideb.hu (N.M.); \\ soares.andrade@med.unideb.hu (C.A.S.A.); kovacs.nora@med.unideb.hu (N.K.); \\ diana.njuguna@med.unideb.hu (D.W.N.) \\ 2 Office for Supported Research Groups, Eötvös Loránd Research Network, 1052 Budapest, Hungary \\ * Correspondence: varga.orsolya@med.unideb.hu
}

Citation: Mahrouseh, N.; Andrade, C.A.S.; Kovács, N.; Njuguna, D.W.; Varga, O. Diabetes Mellitus and Associated Factors in Slovakia: Results from the European Health Interview Survey 2009, 2014, and 2019. Nutrients 2021, 13, 2156 https://doi.org/10.3390/nu13072156

Academic Editor: Panagiota Mitrou

Received: 15 May 2021

Accepted: 21 June 2021

Published: 23 June 2021

Publisher's Note: MDPI stays neutral with regard to jurisdictional claims in published maps and institutional affiliations.

Copyright: (c) 2021 by the authors. Licensee MDPI, Basel, Switzerland. This article is an open access article distributed under the terms and conditions of the Creative Commons Attribution (CC BY) license (https:// creativecommons.org/licenses/by/ $4.0 /)$.

\begin{abstract}
Diabetes mellitus (DM) is a high-risk non-communicable disease with an emerging burden for the European Union (EU) member states in the past decades. The unfavorable trend of the burden is striking compared to the declining disease burden due to cardiovascular diseases or stagnation of neoplasms. The goal of this study is to describe the temporal changes of diabetes in the adult population of Slovakia through the three European Health Interview Survey (EHIS) waves and to assess the association between DM and socioeconomic and/or lifestyle characteristics. These cross-sectional studies were carried out using microdata derived from Slovakia's EHISs conducted in the years 2009 ( $n=4972), 2014(n=5490)$, and 2019 ( $n=5527)$. The DM variable was compared to the independent variables such as sociodemographic and lifestyle characteristics including dietary patterns and physical activity. DM prevalence for the EHIS in 2009, 2014, and 2019 were 6.1\%, 8.2\%, and $9.8 \%$, respectively. In bivariate analysis, the relationship between DM and age, education level, job status, BMI, walking for at least $10 \mathrm{~min}$, and physical activity was significant in the three EHISs. In 2014 and 2019, there was an inverse association between the risk of DM and walking regularly. There was no association between the frequency of eating fruits or vegetables and DM, with the exception of 2009, where a negative association between eating vegetables one to six times a week and DM was observed. Present health policies and activities in Slovakia were unable to reverse the increasing DM burden, indicating that a more systematic approach is needed. Complex policy strategies and legislative measures must be developed and implemented at both the national and EU levels.
\end{abstract}

Keywords: EHIS; diabetes; disease burden; European Union; policies

\section{Introduction}

Diabetes mellitus (DM) and its complications rank high in the global list of diseases with high burden values [1]. DM is one of the four most common chronic noncommunicable diseases (NCDs), which occurs due to inadequate insulin production in the pancreas, or when the body does not use its insulin production properly, which impact blood sugar regulation. Uncontrolled DM can lead to several systemic complications in the body. According to the World Health Organization (WHO), the three major types of DM are type 1 diabetes mellitus, type 2 diabetes mellitus (T2DM), and gestational diabetes. Among these, the T2DM is by far the most common, accounting for $90 \%$ of total DM cases. With regard to its frequency and preventability, policies and strategies for the prevention of DM are mainly tackling diabetes T2DM risk factors [2,3]. The European Union (EU) member states are especially facing an increasing burden of DM; projections for 2030 and 2045 show that the prevalence of DM among adults will increase to $50.48 \%$ and 50.51\%, respectively [4]. Such a trend is very unfavorable compared to the two other major NCDs-cardiovascular 
diseases and neoplasms. According to the Global Burden of Disease (GBD) database, the trend of DALYs (age-standardized rate per 100,000) due to cardiovascular diseases showed a considerable decline from 8477.91 in 1990 to 5779.75 in 2019. Neoplasms had a plateau in trend with modest change on DALYs from 5752.73 in 1990 to 6022.41 in 2019. In the same time period, DM was reported to show a significant increase of burden, from 741.63 to 1098.57 [1].

In European countries, efforts have been made to tackle DM since the establishment of the St. Vincent Declaration in 1989. Although some political initiatives by the European Parliament were taken [5], in the last 20 years, DM has been mostly addressed as one of the NCDs-for example, the Action Plan for the Prevention and Control of Non-communicable Diseases in the WHO European Region [6].

However, according to Article 168 of the Treaty on the Functioning of the European Union, the member states have the primary role of organizing the healthcare services; the EU provides support and funds for prevention and research to reduce the burden due to DM in many ways [7] - for instance, by facilitating the production of comparable datasets for the identification and adoption of effective health policy measures. The European Health Interview Survey (EHIS) is the most significant health data collection instrument. It provides information on the health status, health determinants and healthcare services facilitating data comparability between the member states [8]. These comparable data allow stakeholders to develop and select tailored responses targeting the causal factors of NCDs.

According to the $\mathrm{WHO}$, the onset of type 2 diabetes can be delayed by maintaining a healthy body weight, being physically active, eating a healthy diet and avoiding tobacco use [9]. Poor diet is one of the major issues implicated in the incidence of DM. High intake of foods with a high quantity of sugar, such sweetened beverages, can lead to worsened DALYs in countries of the EU. Moreover, the suboptimal consumption of whole grains, nuts, fruit, fish and legumes have a negative impact on the burden of DM [10]. Increased physical activity, exercise or training, and reduced sedentary lifestyle are also behaviors needed to avoid the occurrence of DM [11].

In addition to lifestyle related factors, socioeconomic factors also influence the development of DM. Population-based studies have reported an association with older age, lower socioeconomic status, and a lower level of education [12]. The burden due to DM varies significantly among member states, and the diversity is present at a subnational and regional level $[13,14]$. Thus, individual-based strategies addressing socioeconomic disadvantages also seem necessary for DM prevention [15].

This study aims to describe the temporal changes of DM in the adult population of Slovakia through the three EHIS waves, and to assess the association between DM and socioeconomic and/or lifestyle characteristics. This study shows important results from an ongoing project analyzing data from the three EHIS waves with a focus on DM in the EU.

\section{Methods}

Cross-sectional studies were carried out using microdata derived from Slovakia's EHISs conducted in $2009(n=4972), 2014(n=5490)$, and $2019(n=5527)$. The microdata was obtained from Eurostat for European Health Interview survey 2009 and 2014, and The Statistical Office of the Slovak Republic for European Health Interview Survey 2019. These samples are representative of the Slovakian adult population (aged 15 years or over) residing in private households. The three surveys included different participants. The EHIS data collection method differs between countries, which may include face-to-face interviews, telephone interviews, postal, web interviews or a combination of these methods. Self-administered questionnaires were also applied for some questions; through papers, the Internet, or both. According to the quality report of wave 2 in Slovakia, face-to-face interviews and self-administered paper-based questionnaires were used. The sampling frame varied by countries as some used population registers, dwelling registers, population censuses, and others. Slovakia's sampling frame was drawn from the dwelling register. 
Some countries used proxy interviews; in Slovakia, proxy interviews were not applied. Details of the methodology and sampling are reported by the European Commission [8]. Our study variables were based on questions consequently asked in the 2009, 2014, and 2019 EHISs. Respondents who answered "yes" to the question: "During the past 12 months, have you had diabetes?" were considered in the group with DM, including any types of diabetes mellitus. Self-reporting sociodemographic and lifestyle characteristics were analyzed as independent variables; a definition of each variable as derived from the survey is available in Supplementary.

Demographic and socioeconomic characteristics included sex, age (15 to 44,45 to 64 , and 65 and above), regions based on level 2 of nomenclature of territorial units for statistics (NUTS2) of Slovakia (Bratislavský kraj, Západné Slovensko, Stredné Slovensko, and Východné Slovensko), degree of urbanization (cities, towns and suburbs and rural areas), education level (less than primary/primary education, secondary education and higher education), labor status (employed, unemployed and others).

The included lifestyle variables were body mass index $\left(B M I, k g / \mathrm{m}^{2}\right)(<18.5,18.5-24.9$, 25-29.9 and $\geq 30$ ), frequency of walking for transportation purposes (to get to and from places) at least $10 \mathrm{~min}$ per day (everyday, one to six days, and never), physical activity per week (two days and more, one day per week and never), the frequency of eating fruits and frequency of eating vegetables per week (one or more per day, one to six times a week, and less than once a week and never).

The distribution of the variables was described and compared within surveys and for diabetic and nondiabetic respondents. Proportions were used as descriptive statistics. The estimated prevalence of DM for each year was based on the study sample. To perform bivariate comparisons, Pearson chi-square test was used to analyze the association between the study variables and DM. A multivariable unconditional logistic regression model was conducted, including variables which were statistically significant in the bivariate analysis, and variables that were not statistically significant, but were of interest from an epidemiological perspective. The regression results are shown as odds ratios (ORs) with $95 \%$ confidence interval (CIs). We used the three datasets separately for analysis. Sampling weights were available in the database; svy function in Stata was used to preserve the EHIS survey weighting only in the multivariable analysis. Statistical analyses were performed by using STATA IC version 13.0 software.

\section{Results}

DM prevalence for the 2009 EHIS was 6.1\%, 8.2\% for 2014, and 9.8\% for 2019. The distribution by numbers of the study population by DM occurrence according to demographic, socioeconomic variables, and lifestyle are shown in Table 1. The distribution by numbers and relative frequencies of the study population divided by the presence of DM according to demographic, socioeconomic variables, and lifestyle are shown in Table S1 of the Supplementary File.

The results of the bivariate analysis showed that the percentage of individuals who had DM differed by gender ( $p$-value $<0.05)$ in 2009; female respondents had higher percentages in the diabetes group than males. Frequencies were significantly different by age groups in 2009, 2014, and 2019: diabetic respondents belonged to older age categories of 65 and older- $3.59 \%, 4.81 \%$, and $6.06 \%$, respectively. It is observed that respondents with secondary education were more affected by DM than any other education levels and the relation between DM and education level is significant. The degree of urbanization presented a significant relationship with DM only in 2009 and 2014; the respondents who had DM and lived in the rural areas were higher in 2009. In 2014, the most individuals with DM lived in towns and suburbs. The occurrence of DM differed by labor status; respondents who were diabetic were higher in other groups (e.g., students, pensioners) of labor status. As seen by the frequencies in the cross-tabulated Table 1, there is a significant relationship between the presence of DM and BMI in 2009, 2014, and 2019. The majority of diabetic individuals belonged to the overweight or obesity group. Individuals with 
DM were higher in the BMI group between 25 to 29.9 in 2009 and 2014, but in 2019, the frequency of diabetes was higher in the BMI group $\geq 30$. The frequency of having DM differed by the number of days walking for at least $10 \mathrm{~min}$ per week. Of the total number of respondents, most of the diabetic individuals in 2009 and 2014 walked to get to and from places one to six times per week for $10 \mathrm{~min}$. Walking every day for transportation purposes was higher and less diabetic individuals never walked in 2009 and 2014. In 2019, respondents with DM had a higher frequency for walking for transportation for $10 \mathrm{~min}$ every day than walking one to six times per week for 10 min or never groups. A significant relationship was shown between the presence of DM and physical activity categories in 2009, 2014, and 2019. Higher frequencies of diabetic individuals were found in the group of individuals who never performed any kind of physical activity per week in 2009, 2014, and 2019. The relationship between the consumption of fruits and vegetables and the presence of DM was significant only in 2009. Diabetic respondents had the highest frequency of eating one or more fruits and vegetables per day in 2009 than eating one to six times a week or less than once a week or never.

The results of the multivariable model are shown in Table 2. The results indicated that females in 2019 were $27 \%$ less likely to have DM compared to males (OR 0.77; 95\% CI 0.62 to 0.95 ). Age groups of 15 to 44 and 45 to 64 had a negative association to DM compared to the reference age group (65 and above) in all three surveys. The degree of urbanization was not associated with the presence of DM. Primary or less than primary education was positively associated with having DM in 2019 (OR 3.25; 95\% CI 1.12 to 9.46) compared to respondents who were in the higher education category. Employment as a labor status had significant lower likelihood of DM, compared to the reference group of other labor status (OR 0.40; 95\% CI 0.27-0.60) (OR 0.35; 95\% CI 0.25-0.49) (OR 0.36; 95\% CI 0.25 to 0.50 ) in the years of 2009, 2014 and 2019. Unemployment (OR 0.56; 95\% CI 0.33 to 0.95 ) presented lower probability of having DM compared to reference group of other labor status, only in 2014.

People with BMI of 30 or higher had a greater probability of developing DM in 2009 and 2019 as compared to the overweight group (BMI 25 to 29.9), and accordingly, lower BMI ( $<18.5$ to 24.9) was associated with a low probability of having DM in 2009 (OR 0.59; 95\% CI 0.41 to 0.84 ), 2014 (OR 0.57; 95\% CI 0.43 to 0.76 ), 2019 (OR $0.65 ; 95 \%$ CI 0.49 to 0.88 ), respectively. Regarding physical activity and movement, a negative association between the risk of DM and walking to get to and from places for at least 10 min every day (OR $0.67 ; 95 \%$ CI 0.49 to 0.92 ) (OR $0.57 ; 95 \%$ CI 0.42 to 0.77 ) or at least one to six times per week (OR 0.70; $95 \%$ CI 0.52 to 0.96 ) (OR 0.69 ; $95 \%$ CI 0.50 to 0.94 ) compared to our reference category of "never" was found in the years of 2014 and 2019, respectively. In 2014, a lack of physical activity, "never", increased the probability of DM (OR 2.55; 95\% 1.02 to 6.37). There was no association between the frequency of eating fruits and the presence of DM. The frequency of eating vegetables one to six times per week compared to our reference category of one and more a day decreased the risk of DM presence in the year 2009 (OR $0.66 ; 95 \% \mathrm{CI} 0.48$ to 0.92 ). There was no significant association regarding regions of Slovakia (data from 2019, exclusively). 
Table 1. Distribution of the study population.

\begin{tabular}{|c|c|c|c|c|c|c|c|c|c|c|}
\hline \multirow[t]{2}{*}{ Variable } & \multirow[t]{2}{*}{ Category } & \multicolumn{3}{|c|}{ EHIS 2009} & \multicolumn{3}{|c|}{ EHIS 2014} & \multicolumn{3}{|c|}{ EHIS 2019} \\
\hline & & With Diabetes $n$ & $\begin{array}{c}\text { Without } \\
\text { Diabetes } n\end{array}$ & $p$-Value & With Diabetes $n$ & $\begin{array}{c}\text { Without } \\
\text { Diabetes } n\end{array}$ & $p$-Value & With Diabetes $n$ & $\begin{array}{c}\text { Without } \\
\text { Diabetes } n\end{array}$ & $p$-Value \\
\hline \multirow{2}{*}{ Sex } & Male & 132 & 2257 & \multirow{2}{*}{0.022} & 184 & 2270 & \multirow{2}{*}{0.098} & 233 & 2087 & \multirow{2}{*}{0.799} \\
\hline & Female & 183 & 2392 & & 265 & 2771 & & 317 & 2898 & \\
\hline \multirow{2}{*}{ Age } & 15 to 44 & Below 20 & 2689 & \multirow{2}{*}{$<0.001$} & $\begin{array}{l}\text { Between } 20 \\
\text { and } 49\end{array}$ & 2467 & \multirow{2}{*}{$<0.001$} & $\begin{array}{l}\text { Between } 20 \\
\text { and } 49\end{array}$ & 1933 & \multirow{2}{*}{$<0.001$} \\
\hline & 65 and older & 178 & 533 & & 264 & 901 & & 335 & 1209 & \\
\hline \multirow{4}{*}{ Region * } & Bratislavský kraj & & & & & & & $\begin{array}{l}\text { Between } 20 \\
\text { and } 49\end{array}$ & 621 & \multirow{4}{*}{0.104} \\
\hline & Západné Slovensko & & & & & & & 194 & 1674 & \\
\hline & Stredné Slovensko & & & & & & & 138 & 1220 & \\
\hline & Východné Slovensko & & & & & & & 160 & 1470 & \\
\hline \multirow[t]{2}{*}{ Degree of urbanization } & Towns and suburbs & 120 & 1445 & \multirow[t]{2}{*}{0.006} & 196 & 2045 & \multirow[t]{2}{*}{$<0.001$} & 178 & 1721 & \multirow[t]{2}{*}{0.342} \\
\hline & Rural areas & 141 & 2095 & & 161 & 1581 & & 249 & 2137 & \\
\hline \multirow{3}{*}{ Education level } & $\begin{array}{l}\text { Primary/less than } \\
\text { primary education }\end{array}$ & Below 20 & 68 & \multirow{3}{*}{0.049} & Below 20 & $\begin{array}{l}\text { Between } 20 \\
\text { and } 49 \\
\end{array}$ & \multirow{3}{*}{$<0.001$} & Below 20 & Below 20 & \multirow{3}{*}{$<0.001$} \\
\hline & Secondary education & 270 & 3724 & & 405 & 4009 & & 482 & 3930 & \\
\hline & Higher education & $\begin{array}{l}\text { Between } 20 \\
\text { and } 49\end{array}$ & 857 & & $\begin{array}{l}\text { Between } 20 \\
\text { and } 49\end{array}$ & 991 & & 51 & 1027 & \\
\hline \multirow{3}{*}{ Labor activity status } & Employed & 66 & 2730 & \multirow{3}{*}{$<0.001$} & 59 & 2393 & \multirow{3}{*}{$<0.001$} & 86 & 2503 & \multirow{3}{*}{$<0.001$} \\
\hline & Unemployed & Below 20 & 299 & & Below 20 & 476 & & Below 20 & 263 & \\
\hline & Others & 241 & 1620 & & 372 & 2172 & & 437 & 2219 & \\
\hline
\end{tabular}


Table 1. Cont.

\begin{tabular}{|c|c|c|c|c|c|c|c|c|c|c|}
\hline \multirow[t]{2}{*}{ Variable } & \multirow[t]{2}{*}{ Category } & \multicolumn{3}{|c|}{ EHIS 2009} & \multicolumn{3}{|c|}{ EHIS 2014} & \multicolumn{3}{|c|}{ EHIS 2019} \\
\hline & & With Diabetes $n$ & $\begin{array}{l}\text { Without } \\
\text { Diabetes } n\end{array}$ & $p$-Value & With Diabetes $n$ & $\begin{array}{c}\text { Without } \\
\text { Diabetes } n\end{array}$ & $p$-Value & With Diabetes $n$ & $\begin{array}{l}\text { Without } \\
\text { Diabetes } n\end{array}$ & $p$-Value \\
\hline & $<18.5$ & Below 20 & 154 & \multirow{4}{*}{$<0.001$} & Below 20 & 131 & \multirow{4}{*}{$<0.001$} & Below 20 & 102 & \multirow{4}{*}{$<0.001$} \\
\hline \multirow{3}{*}{$\mathrm{BMI}\left(\mathrm{kg} / \mathrm{m}^{2}\right)$} & 18.5 to 24.9 & 60 & 2212 & & 88 & 2206 & & 81 & 1883 & \\
\hline & 25 to 29.9 & 130 & 1529 & & 222 & 1888 & & 205 & 1949 & \\
\hline & $\geq 30$ & 109 & 598 & & 138 & 816 & & 243 & 971 & \\
\hline \multirow{2}{*}{$\begin{array}{l}\text { Frequency of walking for } \\
\text { transportation purposes } \\
\text { for at least } 10 \mathrm{~min} \\
\text { continuously per week }\end{array}$} & One to six days & 116 & 1989 & \multirow[t]{2}{*}{$<0.001$} & 188 & 2114 & \multirow[t]{2}{*}{$<0.001$} & 195 & 1690 & \multirow[t]{2}{*}{$<0.001$} \\
\hline & Never & 65 & 429 & & 85 & 546 & & 99 & 422 & \\
\hline \multirow{3}{*}{ Physical activity } & 2 Days and more & 138 & 2996 & \multirow{3}{*}{$<0.001$} & $\begin{array}{l}\text { Between } 20 \\
\text { and } 29\end{array}$ & 1503 & \multirow{3}{*}{$<0.001$} & 53 & 1406 & \multirow{3}{*}{$<0.001$} \\
\hline & One day per week & $\begin{array}{l}\text { Between } 20 \\
\text { and } 49\end{array}$ & 259 & & below 20 & 230 & & Below 20 & 200 & \\
\hline & Never & 143 & 1132 & & 399 & 3308 & & 476 & 3378 & \\
\hline \multirow{2}{*}{$\begin{array}{l}\text { Frequency of } \\
\text { eating fruits }\end{array}$} & $\begin{array}{l}\text { One to six times } \\
\text { a week }\end{array}$ & 69 & 1492 & \multirow[t]{2}{*}{0.001} & 204 & 2353 & \multirow[t]{2}{*}{0.185} & 226 & 1993 & \multirow[t]{2}{*}{0.701} \\
\hline & $\begin{array}{l}\text { Less than once a } \\
\text { week and never }\end{array}$ & Below 20 & 193 & & $\begin{array}{l}\text { Between } 20 \\
\text { and } 49 \\
\end{array}$ & 286 & & $\begin{array}{l}\text { Between } 20 \\
\text { and } 49 \\
\end{array}$ & 308 & \\
\hline \multirow{3}{*}{$\begin{array}{l}\text { Frequency of eating } \\
\text { vegetables or salad }\end{array}$} & Once and more a day & 191 & 2366 & \multirow{3}{*}{0.001} & 192 & 2220 & \multirow{3}{*}{0.843} & 248 & 2363 & \multirow{3}{*}{0.693} \\
\hline & $\begin{array}{c}\text { One to six times } \\
\text { a week }\end{array}$ & 104 & 2023 & & 230 & 2539 & & 255 & 2333 & \\
\hline & $\begin{array}{l}\text { Less than a week } \\
\text { and never }\end{array}$ & Below 20 & 247 & & $\begin{array}{l}\text { Between } 20 \\
\text { and } 49\end{array}$ & 282 & & $\begin{array}{l}\text { Between } 20 \\
\text { and } 49\end{array}$ & 287 & \\
\hline
\end{tabular}

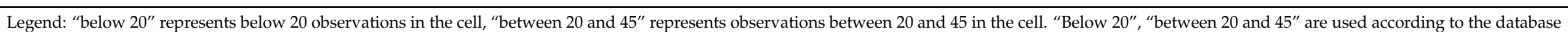

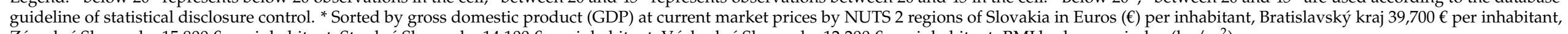
Západné Slovensko 15,800 € per inhabitant, Stredné Slovensko 14,100 € per inhabitant, Východné Slovensko 12,200 € per inhabitant. BMI body mass index (kg/m²). 
Table 2. Factors associated with diabetes Variable.

\begin{tabular}{|c|c|c|c|c|}
\hline Variable & Category & EHIS 2009 & EHIS 2014 & EHIS 2019 \\
\hline & & OR $(95 \% \mathrm{CI})$ & OR $(95 \% \mathrm{CI})$ & OR $(95 \% \mathrm{CI})$ \\
\hline Sex (ref: males) & Female & $0.85(0.64-1.14)$ & $0.91(0.73-1.13)$ & $0.77(0.62-0.95)$ * \\
\hline Age (ref: 65 and older) & 45 to 64 & $0.46(0.32-0.65) *$ & $0.54(0.41-0.71) *$ & $0.71(0.54-0.95)$ * \\
\hline \multirow{3}{*}{ Region (ref: Bratislavský kraj) } & Západné Slovensko & & & $0.83(0.52-1.31)$ \\
\hline & Stredné Slovensko & & & $0.90(0.57-1.44)$ \\
\hline & Východné Slovensko & & & $0.92(0.58-1.46)$ \\
\hline \multirow[b]{2}{*}{ Degree of urbanization (ref: rural areas) } & Cities & $0.82(0.55-1.22)$ & $0.82(0.60-1.11)$ & $1.19(0.87-1.63)$ \\
\hline & Towns and suburbs & $1.19(0.87-1.63)$ & $1.14(0.89-1.45)$ & $1.03(0.82-1.30)$ \\
\hline \multirow[t]{2}{*}{ Education level (ref: higher education) } & $\begin{array}{l}\text { Primary/less than primary } \\
\text { education }\end{array}$ & $0.38(0.10-1.43)$ & $1.23(0.47-3.22)$ & $3.25(1.12-9.46)$ * \\
\hline & Secondary education & $0.71(0.48-1.06)$ & $1.29(0.89-1.88)$ & $1.36(0.97-1.92)$ \\
\hline Labor status (ref: others) & Employed & $0.40(0.27-0.60) *$ & $0.35(0.25-0.49) *$ & $0.36(0.25-0.50)$ * \\
\hline \multirow{3}{*}{ BMI $\left(\mathrm{kg} / \mathrm{m}^{2}\right)$ (ref: 25 to 29.9$)$} & $<18.5$ & $0.64(0.15-2.69)$ & $0.08(0.01-0.56)$ & $1.04(0.34-3.13)$ \\
\hline & 18.5 to 24.9 & $0.59(0.41-0.84) *$ & $0.57(0.43-0.76) *$ & $0.65(0.49-0.88)$ * \\
\hline & $\geq 30$ & $1.81(1.30-2.52) *$ & $1.11(0.86-1.44)$ & $2.04(1.62-2.57)$ * \\
\hline \multirow{2}{*}{$\begin{array}{l}\text { Frequency of walking for transportation purposes for } \\
\text { at least } 10 \text { min continuously per week (ref: never) }\end{array}$} & Everyday & $0.76(0.51-1.14)$ & $0.67(0.49-0.92) *$ & $0.57(0.42-0.77)$ * \\
\hline & One to six days & $0.76(0.51-1.13)$ & $0.70(0.52-0.96) *$ & $0.69(0.50-0.94)$ * \\
\hline \multirow{2}{*}{ Physical activity (ref: one day per week) } & Two days and more & $0.65(0.38-1.11)$ & $1.53(0.59-3.96)$ & $0.63(0.31-1.31)$ \\
\hline & Neve & $0.95(0.55-1.64)$ & $2.55(1.02-6.37) *$ & $1.43(0.73-2.81)$ \\
\hline \multirow{2}{*}{ Frequency of eating fruits (ref: one or more per day) } & One to six times a week & $0.96(0.67-1.39)$ & $0.98(0.73-1.32)$ & $1.10(0.81-1.51)$ \\
\hline & Less than once a week and never & $1.18(0.55-2.51)$ & $1.54(0.87-2.71)$ & $1.07(0.59-1.92)$ \\
\hline \multirow{2}{*}{$\begin{array}{l}\text { Frequency of eating vegetables or salad (ref: one or } \\
\text { more per day) }\end{array}$} & One to six times a week & $0.66(0.48-0.92) *$ & $1.07(0.80-1.44)$ & $0.82(0.60-1.11)$ \\
\hline & Less than a week and never & $0.67(0.34-1.30)$ & $0.79(0.41-1.52)$ & $0.80(0.46-1.39)$ \\
\hline
\end{tabular}




\section{Discussion}

To the best of our knowledge, this is the first study analyzing DM burden throughout the three waves of EHIS. Our study presents nationwide, representative data on an adult population covering basic health monitoring indicators, establishing the required baseline data for future evaluation. According to our analysis, the prevalence of DM patients has shifted upwards from 2009 to 2019. This increase is similar to the increase of prevalence in most of the EU member states and the EU average [16].

The results showed that the degree of urbanization was not associated with the risk of DM, contrary to results from a meta-analysis, which considered living in cities would elevate the risk of DM [17]. Socioeconomic factors such as lower education attainment level and labor status may function as factors due to various disparities in the population $[18,19]$. Results from Denmark and other European countries demonstrate that individuals who are less educated are prone to develop DM than those without. Employment is inversely linked to DM in the three waves; studies have found that individuals with DM exit labor earlier, in addition to reducing their quality of work [20]. Studies suggest that the work environment, type of work and working hours increase the risk of DM [21-23].

Dietary habits have shifted in all EU countries to a "Westernized" diet based on the globalization of food production and distribution, which is most striking in the Mediterranean countries [24]. The vegetable intake in Europe increased by approximately $20 \%$ from the middle of the last century until 2006. Historically, countries of southern Europe reported the highest vegetable intake (double other European regions), but in the beginning of this century, it has started to decrease. Fruit consumption has increased across Europe over the past 60 years, in line with vegetable consumption. Market sales of fruit increased until the beginning of the 21st century, followed by a slow decline. At a regional level, the most significant growth was observed in Northern European countries, where it has been slowly declining in recent years [25].

Our study has supported the already established evidence of the association between obesity and overweight with higher DM risk, which was revealed significantly through the three waves. Fruit and vegetable intake is often at the center of health policies tackling DM. In some prospective studies, fruit and vegetable consumption was found to reduce the risk of DM [26,27]. However, in our cross-sectional analyses, their consumption did not show a consistent association with DM occurrence. People with DM may consume similar amounts of fruits and vegetables as individuals without DM following healthcare recommendations [6,7]. This contradiction is not surprising; the lack of a clear link between total vegetable and fruit consumption and the incidence of T2DM was already reported by a meta-analysis [28].

In high-income countries such as Slovakia, DM occurrence may be more associated with obesity and physical inactivity than other socioeconomic factors and urbanization. This might be caused by diet transitioning towards Westernized diet in recent years. The dietary quality of a country may depend on interrelated factors including traditional food patterns, local food availability, the food supply chain, and food policies.

Sedentary lifestyle, decreased physical activity, is more so than an unhealthy diet considered to be associated directly or indirectly with DM. A study using data from Sport and Physical Activity EU Special Eurobarometers reported that sedentary behavior became more prevalent from 2005 to 2017 in the EU member states (except for Finland) and this increasing prevalence occurred in the total population, and men and women separately. The higher prevalence of sedentary lifestyle was observed among men than women, except for Bulgaria, Estonia, Hungary, Latvia and Lithuania [29].

Based on our results, walking as part of active transportation was a protective factor for DM, which aligns with results from a dose-response meta-analysis; walking up to two to three hours per week reduces the risk of DM, but above these levels, there is no reduction in the risk [30]. Individuals who had a sedentary lifestyle were associated with DM. Clinical trials and cohorts found that both aerobic and resistance exercise have 
an inverse association with DM risk [31]. Meta-analysis suggests a greater risk of DM associated with a large duration of sedentary behavior [32].

Human studies have supported that DM can be delayed or managed integrating a multi-component approach including the main affecting socioeconomic and lifestyle factors through regulating food intake, behavioral changes, and physical activity. A recent randomized controlled trial found that intensive lifestyle interventions resulted in significant weight loss over 12 months, and that more than $60 \%$ of participants experienced the remission of diabetes and 30\% achieved normoglycemia [33].

Although Slovakia has already established legislative efforts in these domains [34,35] which include a policy on the organization of sport in educational settings and promoting sport in younger ages, as well as a national action plan to promote sport and physical activity, several nutritional and labeling policies targeting obesity and improving health, and a national DM plan — the burden of DM is still high [36]. However, the experience with policy interventions at the population level is controversial. While population-based interventions are often followed by some successes, these do not necessarily translate into long-term reductions in disease burden. A systematic review, for example, about regulatory interventions targeting population nutrition found that some "isolated regulatory interventions" may have a positive impact on intermediate outcomes, but this change has not reached clinically significant levels-e.g., having such an impact on food intake that can result in reduced incidence of obesity or NCDs [37]. Similarly, another systematic review has not found evidence of the impact of any of the studied interventions on the prevalence of overweight, obesity, or T2DM [38]. Simulation studies project that a network of interventions is needed to achieve the targets in disease burden reduction. In a model with all potential interventions incorporated, the population risk ratios could be reduced both for obesity and T2DM [39].

The major limitation of this study is that, due to the cross-sectional design, causal relationship between DM and risk factors cannot be established. In our analysis, the employment position was not considered. Regions of level 2 of nomenclature of territorial units for statistics (NUTS2) were only available in 2019; thus, the association between DM and living in different regions of Slovkia was studied in 2019 exclusively. EHIS is a self-reported survey; all answers were subjective, which may affect the accuracy and reliability of the reported data and estimated associations. Additionally, due to the homogenous category of DM that was used in the EHIS waves, the different types of DM were not distinguished in our analysis, although the background pathologies of each type are different.

\section{Conclusions}

Lifestyle characteristics such as dietary habits of eating fruit and vegetables were not associated with DM, but results from 2009 demonstrated that eating vegetables several times a week may reduce the risk of DM and movement for at least $10 \mathrm{~min}$, as walking may prevent DM. However, more lifestyle characteristics and socioeconomic conditions should be studied to evaluate their role in the increased prevalence in Slovakia and in comparison to other EU countries. In the EU, the member states have a leading role in combating DM and its risk factors, to make legislation and provide healthcare services. In Slovakia, existing health policies and actions could not reverse the gradually growing DM burden, indicating that a more systematic approach should be adopted. In conclusion, to achieve improvement, creating and implementing complex policy initiatives and legislative measures seem unavoidable, both at national and EU levels.

Supplementary Materials: The following are available online at https:/ /www.mdpi.com/article/10 $.3390 /$ nu13072156/s1. Table S1: Distribution of the study population. Definitions of the variables that were used in the study. 
Author Contributions: Conceptualization, N.M. and O.V.; data curation, N.M.; formal analysis, N.M., C.A.S.A., N.K., D.W.N. and O.V.; funding acquisition, O.V.; methodology, N.M., C.A.S.A. and O.V.; supervision, O.V.; writing—original draft, N.M.; writing—review and editing, N.M., C.A.S.A., N.K., D.W.N. and O.V. All authors have read and agreed to the published version of the manuscript.

Funding: This work was supported by the GINOP-2.3.2-15-2016-00005 project, co-financed by the European Union under the European Social Fund and European Regional Development Fund. O.V. receives a fellowship from the Hungarian Academy of Sciences (Premium Postdoctoral Research Program).

Institutional Review Board Statement: The Ethical Committee of the Hungarian Scientific Council on Health has approved the research protocol and methodology (61327-2017/EKU).

Informed Consent Statement: Not applicable.

Data Availability Statement: Microdata of EHIS 2009 and 2014 are available via Eurostat upon request. Microdata of EHIS 2019 is available via Statistical Office of the Slovak Republic upon request.

Acknowledgments: We express our gratitude to Eurostat microdata team and to Statistical Office of the Slovak Republic.

Conflicts of Interest: The authors declare no conflict of interest. The funders had no role in the design of the study; in the collection, analyses, or interpretation of data; in the writing of the manuscript, or in the decision to publish the results.

Disclaimer: The responsibility for all conclusions drawn from the data lies entirely with the authors.

Source of the Data: This study is based on data from Eurostat, European Health Interview survey 2009, 2014, and Statistical Office of the Slovak Republic, European Health Interview Survey, 2019.

\section{References}

1. Institute for Health Metrics and Evaluation (IHME). GBD Compare; IHME, University of Washington: Seattle, WA, USA, 2019.

2. World Health Organization. Fact Sheets: Diabetes. Available online: https://www.who.int/news-room/fact-sheets/detail/ diabetes (accessed on 15 May 2021).

3. International Diabetes Federation (IDF). Type 2 Diabetes. Available online: https://idf.org/aboutdiabetes/type-2-diabetes.html (accessed on 15 May 2021).

4. International Diabetes Federation. IDF Diabetes Atlas, 9th ed.; International Diabetes Federation: Brussels, Belgium, 2019.

5. European Parliament. European Parliament News: Parliament Calls for EU Diabetes Strategy. Available online: https:// www.europarl.europa.eu/news/en/press-room/20120313IPR40731/parliament-calls-for-eu-diabetes-strategy (accessed on 15 May 2021).

6. World Health Organization. Action Plan for the Prevention and Control of Noncommunicable Diseases in the WHO European Region. In Proceedings of the Regional Committee for Europe 66th Session 2016, Copenhagen, Denmark, 12-15 September 2016.

7. European Commission. Non-Communicable Diseases Overview. Available online: https://ec.europa.eu/health/non_ communicable_diseases/overview_en (accessed on 27 March 2021).

8. Eurostat. Glossary: European Health Interview Survey (EHIS). Available online: https://ec.europa.eu/eurostat/statisticsexplained/index.php/Glossary:European_health_interview_survey_(EHIS) (accessed on 27 March 2021).

9. World Health Organization. Diabetes Mellitus. Fact Sheet, no. 138. April 2002. Available online: https://www.who.int/healthtopics / diabetes (accessed on 13 May 2021).

10. Schwingshackl, L.; Knüppel, S.; Michels, N.; Schwedhelm, C.; Hoffmann, G.; Iqbal, K.; De Henauw, S.; Boeing, H.; Devleesschauwer, B. Intake of 12 food groups and disability-adjusted life years from coronary heart disease, stroke, type 2 diabetes, and colorectal cancer in 16 European countries. Eur. J. Epidemiol. 2019, 34, 765-775. [CrossRef]

11. Carbone, S.; Del Buono, M.G.; Ozemek, C.; Lavie, C.J. Obesity, risk of diabetes and role of physical activity, exercise training and cardiorespiratory fitness. Prog. Cardiovasc. Dis. 2019, 62, 327-333. [CrossRef] [PubMed]

12. Seiglie, J.A.; Marcus, M.-E.; Ebert, C.; Prodromidis, N.; Geldsetzer, P.; Theilmann, M.; Agoudavi, K.; Andall-Brereton, G.; Aryal, K.K.; Bicaba, B.W.; et al. Diabetes Prevalence and Its Relationship With Education, Wealth, and BMI in 29 Low- and Middle-Income Countries. Diabetes Care 2020, 43, 767-775. [CrossRef] [PubMed]

13. Schipf, S.; Ittermann, T.; Tamayo, T.; Holle, R.; Schunk, M.; Maier, W.; Meisinger, C.; Thorand, B.; Kluttig, A.; Greiser, K.H.; et al. Regional differences in the incidence of self-reported type 2 diabetes in Germany: Results from five population-based studies in Germany (DIAB-CORE Consortium). J. Epidemiol. Commun. Health 2014, 68, 1088-1095. [CrossRef]

14. Du, Y.; Baumert, J.; Paprott, R.; Teti, A.; Heidemann, C.; Scheidt-Nave, C. Factors associated with undiagnosed type 2 diabetes in Germany: Results from German Health Interview and Examination Survey for Adults 2008-2011. BMJ Open Diabetes Res. Care 2020, 8, e001707. [CrossRef] 
15. Rawshani, A.; Svensson, A.-M.; Zethelius, B.; Eliasson, B.; Rosengren, A.; Gudbjörnsdottir, S. Association Between Socioeconomic Status and Mortality, Cardiovascular Disease, and Cancer in Patients with Type 2 Diabetes. JAMA Intern. Med. 2016, 176, 1146-1154. [CrossRef]

16. Global Burden of Disease Collaborative Network. Global Burden of Disease Study 2019 (GBD 2019) Results; Global Burden of Disease Collaborative Network: Seattle, WA, USA, 2020.

17. Braver, N.R.D.; Lakerveld, J.; Rutters, F.; Schoonmade, L.J.; Brug, J.; Beulens, J.W.J. Built environmental characteristics and diabetes: A systematic review and meta-analysis. BMC Med. 2018, 16, 1-26. [CrossRef]

18. Kumari, M.; Head, J.; Marmot, M. Prospective Study of Social and Other Risk Factors for Incidence of Type 2 Diabetes in the Whitehall II Study. Arch. Intern. Med. 2004, 164, 1873-1880. [CrossRef]

19. Stringhini, S.; Zaninotto, P.; Kumari, M.; Kivimäki, M.; Batty, G.D. Lifecourse socioeconomic status and type 2 diabetes: The role of chronic inflammation in the English Longitudinal Study of Ageing. Sci. Rep. 2016, 6, 24780. [CrossRef] [PubMed]

20. Rumball-Smith, J.; Barthold, D.; Nandi, A.; Heymann, J. Diabetes Associated with Early Labor-Force Exit: A Comparison of Sixteen High-Income Countries. Health Aff. 2014, 33, 110-115. [CrossRef] [PubMed]

21. Magadzire, B.P.; Mathole, T.; Ward, K. Reasons for missed appointments linked to a public-sector intervention targeting patients with stable chronic conditions in South Africa: Results from in-depth interviews and a retrospective review of medical records. BMC Fam. Pract. 2017, 18, 1-10. [CrossRef] [PubMed]

22. Pazmino, L.; Esparza, W.; Aladro-Gonzalvo, A.; León, E. Impact of Work and Recreational Physical Activity on Prediabetes Condition among U.S. Adults: NHANES 2015-2016. Int. J. Environ. Res. Public Health 2021, 18, 1378. [CrossRef] [PubMed]

23. Kang, E. Differences in Clinical Indicators of Diabetes, Hypertension, and Dyslipidemia Among Workers Who Worked Long Hours and Shift Work. Workplace Health Saf. 2021, 69, 268-276. [CrossRef] [PubMed]

24. Vareiro, D.; Bach-Faig, A.; Quintana, B.R.; Bertomeu, I.; Buckland, G.; De Almeida, M.D.V.; Serra-Majem, L. Availability of Mediterranean and non-Mediterranean foods during the last four decades: Comparison of several geographical areas. Public Health Nutr. 2009, 12, 1667-1675. [CrossRef] [PubMed]

25. Riccardi, G.; Vitale, M.; Vaccaro, O. Are Europeans moving towards dietary habits more suitable for reducing cardiovascular disease risk? Nutr. Metab. Cardiovasc. Dis. 2020, 30, 1857-1860. [CrossRef] [PubMed]

26. Jiang, Z.; Sun, T.-Y.; He, Y.; Gou, W.; Zuo, L.-S.-Y.; Fu, Y.; Miao, Z.; Shuai, M.; Xu, F.; Xiao, C.; et al. Dietary fruit and vegetable intake, gut microbiota, and type 2 diabetes: Results from two large human cohort studies. BMC Med. 2020, 18, 1-11. [CrossRef] [PubMed]

27. Cooper, A.; Sharp, S.J.; Lentjes, M.; Luben, R.; Khaw, K.-T.; Wareham, N.J.; Forouhi, N.G. A Prospective Study of the Association Between Quantity and Variety of Fruit and Vegetable Intake and Incident Type 2 Diabetes. Diabetes Care 2012, 35, 1293-1300. [CrossRef]

28. Neuenschwander, M.; Ballon, A.; Weber, K.S.; Norat, T.; Aune, D.; Schwingshackl, L.; Schlesinger, S. Role of diet in type 2 diabetes incidence: Umbrella review of meta-analyses of prospective observational studies. BMJ 2019, 366, 12368. [CrossRef]

29. López-Valenciano, A.; Mayo, X.; Liguori, G.; Copeland, R.J.; Lamb, M.; Jimenez, A. Changes in sedentary behaviour in European Union adults between 2002 and 2017. BMC Public Health 2020, 20, 1-10. [CrossRef]

30. Aune, D.; Norat, T.; Leitzmann, M.; Tonstad, S.; Vatten, L.J. Physical activity and the risk of type 2 diabetes: A systematic review and dose-response meta-analysis. Eur. J. Epidemiol. 2015, 30, 529-542. [CrossRef]

31. Ross, L.M.; Slentz, C.A.; Zidek, A.M.; Huffman, K.M.; Shalaurova, I.; Otvos, J.D.; Connelly, M.A.; Kraus, V.B.; Bales, C.W.; Houmard, J.A.; et al. Effects of Amount, Intensity, and Mode of Exercise Training on Insulin Resistance and Type 2 Diabetes Risk in the STRRIDE Randomized Trials. Front. Physiol. 2021, 12. [CrossRef]

32. Bailey, D.P.; Hewson, D.J.; Champion, R.B.; Sayegh, S.M. Sitting Time and Risk of Cardiovascular Disease and Diabetes: A Systematic Review and Meta-Analysis. Am. J. Prev. Med. 2019, 57, 408-416. [CrossRef] [PubMed]

33. Taheri, S.; Zaghloul, H.; Chagoury, O.; Elhadad, S.; Ahmed, S.H.; El Khatib, N.; Amona, R.A.; El Nahas, K.; Suleiman, N.; Alnaama, A.; et al. Effect of intensive lifestyle intervention on bodyweight and glycaemia in early type 2 diabetes (DIADEM-I): An open-label, parallel-group, randomised controlled trial. Lancet Diabetes Endocrinol. 2020, 8, 477-489. [CrossRef]

34. Richardson, E.; Zaletel, J.; Ellen, N. National Diabetes Plans: In Europe What Lessons Are there for the Prevention and Control of Chronic Diseases in Europe? National Institute of Public Health Ljubljana: Ljubljana, Slovenia, 2016.

35. World Health Organization. Diabetes Country Profiles: Slovakia. Available online: https://www.who.int/diabetes/countryprofiles/svk_en.pdf (accessed on 15 May 2021).

36. World Obesity Federation. Global Obesity Observatory. Available online: https://data.worldobesity.org/ (accessed on 15 May 2021).

37. Sisnowski, J.; Street, J.M.; Merlin, T. Improving food environments and tackling obesity: A realist systematic review of the policy success of regulatory interventions targeting population nutrition. PLoS ONE 2017, 12, e0182581. [CrossRef]

38. Roberts, S.; Pilard, L.; Chen, J.; Hirst, J.; Rutter, H.; Greenhalgh, T. Efficacy of population-wide diabetes and obesity prevention programs: An overview of systematic reviews on proximal, intermediate, and distal outcomes and a meta-analysis of impact on BMI. Obes. Rev. 2019, 20, 947-963. [CrossRef] [PubMed]

39. Nianogo, R.A.; Arah, O.A. Impact of Public Health Interventions on Obesity and Type 2 Diabetes Prevention: A Simulation Study. Am. J. Prev. Med. 2018, 55, 795-802. [CrossRef] 